\title{
DEA based approach to set energy efficiency target under PAT Framework: A case of Indian cement industry
}

\author{
Anoop SINGH, Bharat SHARMA \\ Indian Institute of Technology Kanpur, India
}

\begin{abstract}
:
Aim: Propose a Data Envelopment Analysis (DEA) based approach to set energy efficiency targets under the Perform, Achieve and Trade (PAT) framework of the Bureau of Energy Efficiency (BEE)
\end{abstract}

Design / Research methods: We adopt input-oriented non-controllable DEA model with variable return to scale DEA

Conclusions / findings: Due to the implication of in-house energv conversion. we estimate separate energy efficiency targets based on "purchased energy" as well as "process energy". The later accounts for energy finally used in the production process after in-house energy conversion.

Originality / value of the article: The Bureau of Energy Efficiency (BEE) in India has introduced a market based energy efficiency mechanism under the Perform, Achieve and Trade (PAT) framework. Under this mechanism, energy efficiency certificates can be traded across eight identified sectors thus bringing cost effectiveness to achieve the energy efficiency targets. To implement the scheme, differentiated energy efficiency targets have been set using baseline specific energy consumption. This approach does not account for technical and operational aspects like vintage, scale, output mix and input mix. This study proposes an alternative target setting method based on Data Envelopment Analysis (DEA) which takes into account some of the above mentioned technical and operational differences across the industrial plants. A comparative assessment highlights the efficacy of DEA methodology in implementation of the PAT scheme. We estimate energy efficiency targets based on "purchased energy" as well as "process energy", i.e. that used finally in the production process.

Implications of the research: BEE may adopt the suggested approach to set energy efficiency targets for subsequent cycles under the Perform, Achieve and Trade (PAT) framework.

Key words: energy efficiency target, PAT framework, Data Envelopment Analysis, Indian cement industry

JEL: Q48, Q49

Correspondence address: Anoop Singh, Department of Industrial and Management Engineering, Indian Institute of Technology Kanpur, India. E-mail: anoops@iitk.ac.in Received: 15-09-2017, Revised: 14-02-2018, Revised: 27-02-2018, Accepted: 27-02-2018 doi: http://dx.doi.org/10.29015/cerem.552 


\section{Introduction}

There is a continuous challenge to balance the tripod of environment, development and resource utilization. Energy efficiency offers a strong case to be pursued for in order to attain this balance. The growing requirement of energy, constrained access to the resources, questions pertaining to energy security, environmental concerns and increasing competitiveness in global markets has driven the urgency to layout strategies to attain higher efficiency in energy utilization.

Policy framework in India has given increasing importance to energy efficiency across different sectors and has addressed it time and again. The Energy Conservation Act, 2001 provides for the various measures to improve energy efficiency in the country. The Act identifies 15 energy intensive industries and establishments as Designated Consumers (DCs) for targeting energy efficiency efforts. The Act led to setting up of the Bureau of Energy Efficiency (BEE), and entrusted it with both promotional and regulatory functions.

While working with the international community on the challenges of global warming, India identified the need for measures and actions at national level to adapt to climate change and to develop in an ecologically sustainable manner. The Prime Minister of India released the National Action Plan on Climate Change (NAPCC) on 30th June 2008. Out of these eight missions, National Mission for Enhanced Energy Efficiency (NMEEE) and National Mission for Sustainable Habitat (NMSH) are related to energy efficiency. NMSH advances the sustainability of human habitats primarily in urban regions by improving energy efficiency in buildings, solid waste management and promoting a modal shift to public transport.

Apart from the previously running programs on energy efficiency by the BEE, NMEEE suggested four more initiatives namely the Market Transformation for Energy Efficiency (MTEE), the Energy Efficiency Financing Platform (EEFP), the Framework for Energy Efficient Economic Development (FEEED) and the Perform Achieve \& Trade (PAT). The PAT mechanism is being implemented under the institutional structure of the BEE. PAT targets the Designated Consumers (DCs) in the industrial sectors which accounts for about $25 \%$ of the nation's GDP and $45 \%$ of the commercial energy consumption in India (Bureau of Energy Efficiency 2012: 1- 
4). Out of the fifteen energy intensive industries notified in the Act, eight industrial sectors are included in first PAT cycle. In 2010, Energy Conservation Act Amendment Bill was passed. This allows the government to issue Energy Saving Certificates (ESCerts) and also allows purchase of these certificated by DCs which fail to meet the targets set under the PAT framework. A penalty would be imposed for the DCs which fail to comply with the energy consumption targets.

The first PAT cycle was rolled out for the financial year 2012-13 to 2014-15. In the first cycle, 478 DCs were included across eight energy intensive sectors. In the second PAT cycle, the depth and width of PAT has been increased. The total number of DCs has been increased to 621 and three more sectors are included viz. Petroleum refinery, railways and electricity distribution companies. While the second PAT cycle had been rolled out, it continues to retain its original flavour.

This paper discusses the methodology adopted under PAT mechanism for target setting for DCs and attempts to provide a Data Envelopment Analysis (DEA) based alternate approach for target setting. DEA is a non-parametric linear programming method in operations research, which builds an efficiency frontier and provides a performance based ranking for the Decision Making Units (DMUs). DEA is a widely applied tool used in different fields including the energy sector. The next section briefly discuss the industrial energy consumption scenario in India. Section 3 presents a review of the PAT framework including the methodology for efficiency target setting for the first cycle and discussion thereof. A brief review of the literature covering application of the DEA in the context of energy efficiency, is presented in section 4 . Section 5 discusses the methodology adopted in the paper and results thereof.

\section{Industrial energy consumption in India}

India consumes about $4.5 \%$ of the world's industrial energy (International Energy Agency 2016). With increasing industrialization and a push for manufacturing, energy consumption is bound to increase. Table 1 shows the sectorwise energy consumption in the Indian economy from year 2010-11 to 2014-15. 
Industrial energy consumption in India is around 50\% of the total energy consumption of the country and, later, remains a focus for energy efficiency improvement.

Table 1. Energy consumption across sectors in Indian economy

\begin{tabular}{|c|c|c|c|c|c|c|c|c|c|c|}
\hline & \multicolumn{2}{|c|}{$\mathbf{2 0 1 0 - 1 1}$} & \multicolumn{2}{c|}{$\mathbf{2 0 1 1 - 1 2}$} & \multicolumn{2}{c|}{$\mathbf{2 0 1 2 - 1 3}$} & \multicolumn{2}{|c|}{$\mathbf{2 0 1 3 - 1 4}$} & \multicolumn{2}{|c|}{$\mathbf{2 0 1 4 - 1 5}$} \\
\hline Sector & $\begin{array}{c}\text { Energy } \\
\text { (kTOE) }\end{array}$ & $\begin{array}{c}\text { Sector } \\
\%\end{array}$ & $\begin{array}{c}\text { Energy } \\
\text { (kTOE) }\end{array}$ & $\begin{array}{c}\text { Sector } \\
\%\end{array}$ & $\begin{array}{c}\text { Energy } \\
\text { (kTOE) }\end{array}$ & $\begin{array}{c}\text { Sector } \\
\%\end{array}$ & $\begin{array}{c}\text { Energy } \\
\text { (kTOE) }\end{array}$ & $\begin{array}{c}\text { Sector } \\
\%\end{array}$ & $\begin{array}{c}\text { Energy } \\
\text { (kTOE) }\end{array}$ & $\begin{array}{c}\text { Sector } \\
\%\end{array}$ \\
\hline Industry & 163282 & 33.05 & 131962 & 46.97 & 167250 & 50.24 & 223805 & 52.72 & 270641 & 55.92 \\
\hline Transport & 58003.5 & 11.74 & 19387 & 6.90 & 25314 & 7.60 & 29104 & 6.86 & 114126 & 23.58 \\
\hline $\begin{array}{c}\text { Others } \\
\text { Residential, } \\
\text { Services, } \\
\text { Agri., etc.) }\end{array}$ & 239693 & 48.51 & 129584 & 46.13 & 122614 & 36.83 & 136501 & 32.16 & 72343 & 14.94 \\
\hline $\begin{array}{c}\text { Non-Energy } \\
\text { use }\end{array}$ & 33105.9 & 6.70 & - & - & 17757 & 5.33 & 35098 & 8.27 & 26841 & 5.54 \\
\hline TOTAL & 494084.4 & & 280933 & & 332935 & & 424508 & & 483951 & \\
\hline
\end{tabular}

Source: GOI (2012, 2013, 2014, 2015, 2016).

\subsection{Energy use pattern in Indian industry}

Energy consumption across various industrial sectors depends on the energy density of the sector in the overall feel of industrial activity. Table 2 shows the distribution of energy consumption across various industrial sectors in India (GOI 2012, 2013, 2014, 2015, 2016).

Energy consumption across the industrial sectors varies depending on technological aspects governing output mix and input mix. Further adoption of captive power generation, internal waste heat recovery and co-generation of electricity and steam also differentiate energy consumption pattern across similar plants. Cement industries one of the large energy consuming sectors, followed by iron and steel sector. 
Table 2. Energy consumption across various industrial sectors in India

\begin{tabular}{|c|c|c|c|c|c|}
\hline Industrial Sector & $\mathbf{2 0 1 0 - 1 1}$ & $\mathbf{2 0 1 1 - 1 2}$ & $\mathbf{2 0 1 2 - 1 3}$ & $\mathbf{2 0 1 3 - 1 4}$ & $\begin{array}{c}\mathbf{2 0 1 4} \\
\mathbf{1 5}\end{array}$ \\
\hline Iron and steel & 25924.5 & 28261 & 37735 & 40793 & 54758 \\
\hline Chemical and petrochemical & 5811.9 & 5897 & 15954 & 12423 & 12595 \\
\hline Non-ferrous metals & 524.5 & 3670 & 12816 & 125 & 20 \\
\hline Non-metallic minerals\$ & 7329.3 & - & 2 & 18 & - \\
\hline Transport equipment & 11848.9 & 171 & 11 & 8 & - \\
\hline Machinery & 35 & 1578 & 77 & 17 & 264 \\
\hline Mining and quarrying & 2797.6 & 1307 & 1110 & 903 & 141 \\
\hline Food \& Tobacco & - & 137 & - & - & - \\
\hline Paper, pulp and print & 1189.2 & 2280 & 1435 & 1288 & 1195 \\
\hline Construction & 109.4 & 12172 & 11009 & 27742 & 26217 \\
\hline Textile and leather & 930.8 & 868 & 451 & 937 & 1004 \\
\hline Non-specified (industry) & 106781 & 75621 & 86650 & 139551 & 174448 \\
\hline $\begin{array}{c}\text { Total Industrial Energy } \\
\text { Consumption (PJ) }\end{array}$ & 163282.1 & 131962 & 167250 & 223805 & 270641 \\
\hline
\end{tabular}

Source: GOI $(2012,2013,2014,2015,2016)$.

Note: $\$$ - including cement industry

\subsection{Cement}

The Indian cement industry is the second largest producer in the world after China and is also a very efficient one. By converting from wet process plants to dry and semi dry process plants, cement industry in India has achieved economy in fuel and power consumption. Of the 13 types of cement produced in India, Ordinary Portland Cement (OPC), Portland Pozzolana Cement (PPC) and Portland blast furnace Slag Cement (PSC) accounted for 39\%, 52\% and $8 \%$ of the total production respectively in the year 2007 (Lawrence Berkeley National Laboratory 2010).

In India, thermal energy consumption for clinker production in the year 2005-06 was averaged to $725 \mathrm{kcal} / \mathrm{kg}$ and electricity consumption for cement production was averaged to $82 \mathrm{kWh} / \mathrm{MT}$ (Planning Commission 2008). A total primary energy consumption of Indian cement Industry was estimated at 700 PJ in the year 2007. Of the total final energy consumption of $580 \mathrm{PJ}$, coal constituted $91 \%$ and electricity share was $9 \%$. Thermal energy intensity for producing $174 \mathrm{MT}$ of cement in the year 
2007 was 3.03 GJ/MT and electrical energy intensity was 0.3 GJ/MT (Lawrence Berkeley National Laboratory 2010).

Coal consumption in the cement industry peaked at 18.097 MT in 2005 while it was 15.08 MT in 2011 with a growth of $2.86 \%$ from the previous year. Electricity consumption was $15311 \mathrm{GWh}$ in 2011 with a decrement of $7.42 \%$. CAGR of coal and electricity consumption from 2006 to 2011 were $1.95 \%$ and $5.09 \%$ respectively (CEIC 2013). Table 3 shows the specific energy consumption for cement sector in different countries including India.

Table 3. Specific energy consumption in cement industry - an international comparison

\begin{tabular}{|c|c|c|}
\hline Country & $\begin{array}{c}\text { Specific Electrical Energy } \\
\text { Consumption }(\mathrm{kWh} / \text { ton of cement) }\end{array}$ & $\begin{array}{c}\text { Specific Thermal Energy } \\
\text { Consumption (kcal/kg of cement) }\end{array}$ \\
\hline India & 82 & 725 \\
\hline Spain & 92 & 836 \\
\hline Germany & 100 & 836 \\
\hline Japan & 100 & 836 \\
\hline Brazil & 110 & 884 \\
\hline Italy & 112 & 908 \\
\hline China & 118 & 956 \\
\hline Mexico & 118 & 1003 \\
\hline Canada & 140 & 1075 \\
\hline USA & 141 & 1099 \\
\hline World Average & $100-110$ & $850-860$ \\
\hline World Best & 65 & 649 \\
\hline
\end{tabular}

Source: Gielen, Taylor (2009); International Energy Agency (2007); Madlool et al. (2011).

The specific energy consumptions of the plants in India were observed to be more than 20-30\% of that of the plants in Japan in 1990 (Singh 2000). After adapting and adopting several measures and continuous improvements, presently Indian cement industry is the most energy efficient in the world (Gielen, Taylor 2009; International Energy Agency 2007). But there is scope for improvement as compared to the best plants in the world and within the country.

\section{Perform, Achieve \& Trade (PAT) mechanism}

PAT is developed as an institutional and regulatory framework to incentivize energy saving and to give a push to the energy efficient industrial production in 
India. It will support use of energy efficient technologies in industries. Under this framework, each designated consumer (DC) is given a "unit specific" specific energy consumption reduction target in terms of percentage reduction in the specific energy consumption (SEC). The tenets followed in PAT framework are accountability, predictability, transparency, consistency, simplicity and adaptability.

\subsection{PAT mechanism}

BEE sets the sectorial targets and unit specific targets for the plants. BEE issues energy saving certificates EScerts to the DCs who overachieve their targets based on the PAD (PAT assessment Document) approved by accredited Designated Energy Agencies (DENA). It coordinates with various state designated agencies (SDAs) for the verification and implementation of the PAT scheme.

These SDAs coordinate with BEE to decentralise the work of monitoring and verification. The SDAs are normally the state level renewable energy agencies. They monitor the compliances by the DCs and levy penalty on them in case of noncompliances. DENA is the independent energy auditor accredited by BEE which verifies and audits the PAD submitted by the DCs for assessment of compliance. The DENA shares the audit report with the SDAs and the BEE.

The DCs have to comply with the target approved by the BEE. It's also the responsibility of the DCs to prepare PAD and appoint an independent DENA. After approval of PAD, a DC request for the issuance of EScerts in case of overachievement or penalty is levied on in case of failure of compliance. After that, to compensate its shortfall DC has to purchase EScert from the power exchanges (PXn) or may sell EScerts to enjoy monetary benefits or may put them in the banking to be used in the next PAT cycle.

\subsection{PAT Target Setting methodology}

In the target setting phase, data was collected from different DCs for the duration of 5 years from year 2005-2006 to year 2009-2010. A baseline data for the baseline year 2009-10 was prepared taking the average of three years from 20072008 to 2009-2010. Target for each DC was specified through public notification. Commencement of the first PAT cycle was from 1 ${ }^{\text {st }}$ April 2012 for duration of three 
years. During this period, DCs were to achieve the target. Monitoring and verification started after April 2013. Based on the cross-verification report, DCs would be issued EScerts or a penalty would be levied. The quantity of underachieved target is to be paid at the prevailing oil prices. For the SEC target setting in subsequent cycles, data for the previous three years is to be collected. The duration of the second PAT cycle is from 2016-17 to 2018-19.

Rule 4 published in The Gazette of India, Extraordinary, Part II, section 3, subsection (i) vide-notification number G.S.R. 269 (E) dated the 30th March, 2012 provides the procedures for establishing energy consumption norms and standards i.e. about SEC calculations and target setting. The sub-sections in the Rule 4 give guidelines for "Normalisation" by considering factors affecting the energy consumption viz. capacity utilization, mix of captive and grid electricity etc.

\section{Normalized SEC $=f($ Reported SEC, Normalisation Factor $)(1)$}

The normalising statistical procedures are to be applied to SEC during baseline and target periods only if capacity utilization (or plant load factor for thermal power plants) has a deviation from baseline year due to uncontrollable factors specified in the Rule 4 viz. natural disasters, rioting or social unrest, changes in government policies and environmental standards and impact of market (sales or shortage of raw materials).

Target setting in PAT is a two-tier process. First, a sector-level target is set based on the overall energy consumption in the sector. Thereafter, a plant-specific target is set for the DC. Due to factors like difference in technology adopted, output mix and raw material mix, plants show a wide range of specific energy consumption. This range is defined as the bandwidth of the sector. Sub-groups are defined based on process or output. A relative SEC is calculated with respect to the most efficient plant of that group. The target reduction of the DC is set as a multiplier for the respective SEC in that group.

We provide a detailed explanation for target setting in the cement sector and juxtapose the same with PAT targets for the first cycle. For each DC in the sector, all types of cement products and exported clinker were converted into an equivalent 
major product using appropriate conversion factors. Following the approach adopted in Singh et al. (2010), the final Gate to Gate $(\mathrm{GtG})$ energy is calculated by taking count of all the thermal energy imported, converting the electrical energy into thermal equivalent, subtracting the electricity exported to the grid and taking count of notional energy for import and export of clinkers. The cement sector had to achieve a reduction of $4.28 \%$ of their consumption during the first PAT cycle. There are seven groups in the cement sector based on the type of major products and processes. Figure 1 shows these groups on the plotted SEC of 85 cement DCs.

\section{Figure 1. Groups in cement sector}

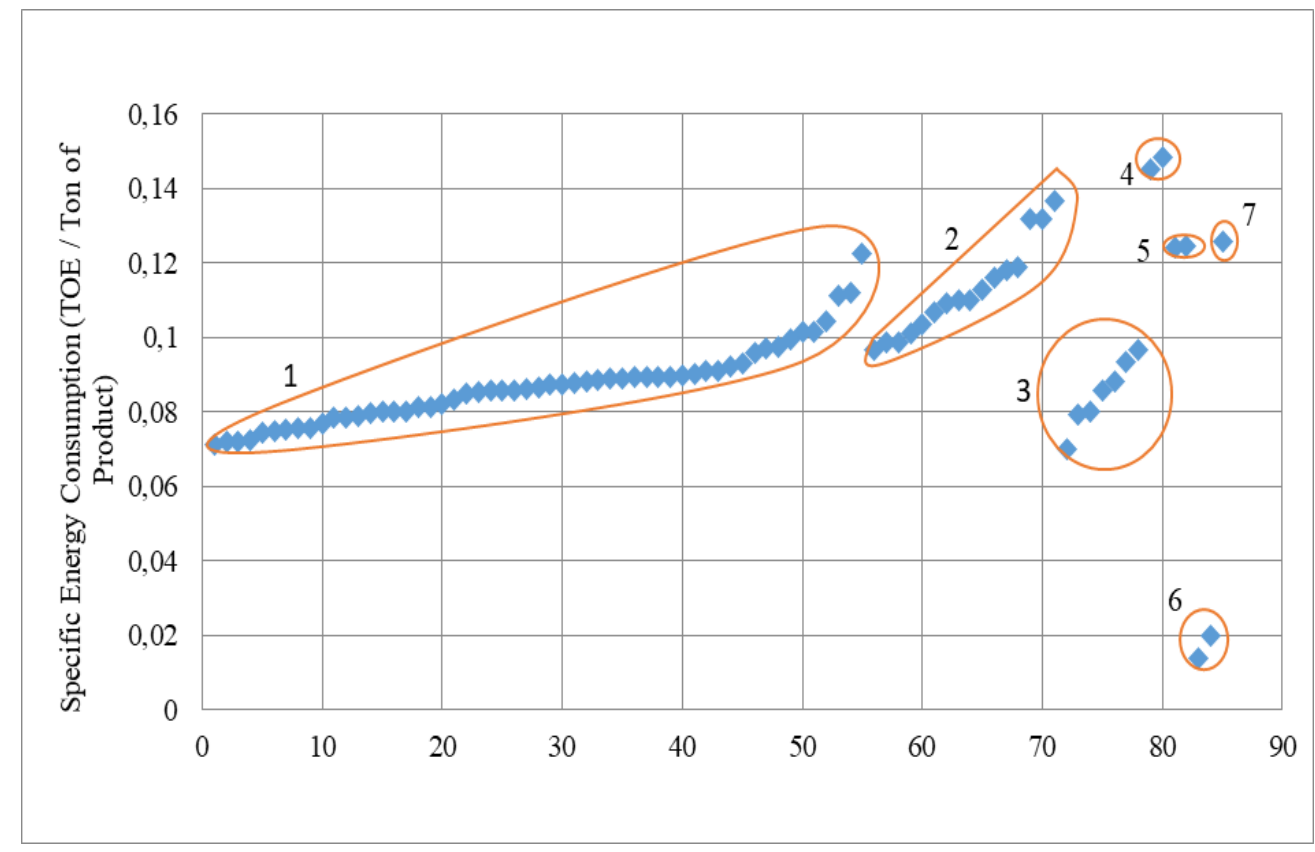

Source: Authors' own elaboration.

Group 1 has 55 plants having major product as PPC. Group 2 is for the 16 plants which have OPC cement as the major product. Group 3 has 7 plants having Portland Slag cement as the major product. Group 4 has 2 white cement plants. Group 5 has 2 wet process based cement plants. Group 6 has 2 plants with only grinding units. Group 7 has only 1 plant which is a "Clinkerization unit".

The energy saving target for a DC will be the product of baseline production and SEC reduction target (Equation 3). The SEC reduction target is the difference of 
SEC calculated for the baseline and the target SEC. The percentage reduction of SEC is product of a multiplier $X$ and the relative SEC (Equation 5). Energy saving by all DCs, when summed up would be equal to the sectoral energy saving target. Following equations are used to calculate the energy saving target for a DC:

$$
\begin{aligned}
& \quad S E C_{i}^{r}=\left(\left(S E C_{i}^{b}\right) /\left(S E C_{i}^{b}\right)\right) \quad(2) \\
& \quad E_{i}^{s}=\left[O_{i}^{b} \times\left(S E C_{i}^{b}-S E C_{i}^{t}\right)\right] \\
& E^{s}=\sum_{i}^{n}\left[O_{i}^{b} \times\left(S E C_{i}^{b}-S E C_{i}^{t}\right)\right] \\
& S E C_{i}^{r} \times X=100 \times\left[\left(S E C_{i}^{b}-S E C_{i}^{t}\right) / S E C_{i}^{b}\right] \\
& \text { Where, } \quad S E C_{i}^{b}=\text { Baseline SEC of DC (MTOE) } \\
& S E C_{i}^{t}=\text { Target SEC for DC (MTOE) } \\
& S E C_{i}^{r}=\text { Relative SEC of DC (MTOE) } \\
& S E C_{i}^{b}=\text { Baseline SEC of the most efficient DC } \\
& X=\text { Multiplying Factor } \\
& O_{i}^{b}=\text { Baseline output of DC (tonnes) } \\
& E_{i}^{s}=\text { Energy saving by a DC } \\
& E^{s}=\text { Total energy saving in the sector }
\end{aligned}
$$

\subsection{PAT critique}

PAT offers a compliance flexibility similar to the emission trading schemes. Excess ECerts, allocated to a DC towards energy saving beyond their SEC target, can be sold via the existing power exchanges (PXs) in the country. DCs, with a target shortfall, can purchase the required number of ECerts to fulfil their reduction target. Anyways Edward shortfall would attract a penalty which is linked to the prevailing oil prices. However, the level of penalty is not enough to dis-incentivise the shortfall in meeting the energy efficiency targets. The methodological approach adopted under the first PAT cycle continues to be saddled with shortcomings. Target energy efficiencies compared to the average annual rate of energy efficiency improvement in the sector. If the target is lesser than the average annual rate of energy efficiency improvement, the actions under PAT mechanism will tend to counter-productive as it will lead to significantly higher supply of ECerts and separating the demand thereof. Based on the oversupply, and the policy for banking, 
this effect will also be carried onward to the subsequent PAT cycles. Subdued prices for Ecerts would, in turn, dis-incentivise long-term investment in efficiency improvement.

The sectoral target for SEC set by BEE is rather lenient. As per IEA data for India from 1991 to 2001, the specific energy consumption in cement sector based on total primary energy supply reduced with CAGR of $4.05 \%$ in that duration (International Energy Agency 2007). The historical reductions in SEC of the cement sector is much more than the relaxed target of $4.28 \%$ (equivalent to $1.43 \%$ per annum) decided by BEE for the first PAT cycle of three-year duration. Internationally, countries have succeeded to achieve annual SEC reduction rates from $1.1 \%$ in Germany to $1.9 \%$ in China. Clearly, the targets set by BEE for the first PAT cycle seems to be lenient.

The benefits from a merit based mechanism like PAT arise due to trade of ECerts between sector DCs with different marginal cost of energy efficiency improvement. For example, the marginal cost curve for aluminium sector is steeper than paper and pulp sector, and would be steeper for DCs with relatively higher energy efficiency i.e. low SEC. The ESCert generated in paper and pulp sector does not represent the same cost and technological advancement required as to the ESCert generated in aluminium sector.

The wide range of specific energy consumption within a sector indicates the potential for the energy saving. It also indicates the variation of plants on factors like vintage, product and raw material mix, technology etc. Acknowledging these variations, BEE has opted for a unit specific target energy reduction instead for a single benchmark. It is evident that it is not feasible to achieve a single benchmark by the unit having highest SEC and unit having lowest SEC. This approach does not completely justify the primary purpose of enhancing energy efficiency in the industrial sector. On the contrary, target setting under PAT framework seems to take a rather lenient view of highly inefficient plants. It also doesn't follow a model with strong theoretical considerations that can compare DCs based on variations on account of output mix and input mix. This can be addressed by the use of Data Envelopment Analysis. Instead of comparing and target setting based on the plant having least SEC, it is more prudent to set the target based on a peer-to-peer 
comparison among plants having similar performance characteristic like scale, energy input etc.

\section{Energy efficiency and DEA: A literature review}

Energy efficiency has been extensively researched and examined based on the requirements in different research domains (engineering, resource management, economics, policy etc.). Greening et al. categorised the employed analytical techniques in four different types (Greening et al. 2007). First, econometric methods used to assess the demand outcome of energy based on prices or energy taxes (e.g. Oh, Lee 2004; Lescaroux 2008). Second, simulation and optimization models based on top-down and bottom-up approach to study the interplay of technology and energy consumption (e.g. Bohringer, Rutherford 2008; Frei et al. 2003). Third are the industry and process specific microeconomic analyses based on simulation, optimization and statistical techniques (e.g., Babusiaux, Pierru 2007; Henning, Trygg 2008; Singh et al. 2010). Fourth type are the decomposition methods like index decomposition analysis (IDA), used to study the effects of morphological change and energy efficiency in the aggregate energy use in a sector or overall for a country (e.g. Alcantara, Duarte 2004; Ang, Zhang 2000; Unander 2004). Bhattacharya and Paul used the decomposition technique to understand the sectorial changes in energy consumption and intensity in India for the duration of year 198095 (Shyamal, Bhattacharya 2004). Nag and Parikh used decomposition method to understand the impact of structural changes, activity levels, fuel mix, and fuel quality and energy intensity on the carbon emission intensity from commercial energy use in India (Nag, Parikh 2000).

The IDA based approach uses the energy intensity as a proxy for energy efficiency and analyses the variations in intensity because of different factors. However, IDA cannot be directly applied to energy efficiency target setting. The benefit of the non-parametric approach of DEA lies in the fact that it uses all factors simultaneously in a total factor framework. DEA uses the concept of efficiency as defined in Farrel (1957) and applies the evaluation methodology as developed by 
Charles et al. (Charnes et al. 1978), thereby avoids the use of imperfect proxies like energy intensity. DEA has received attention in the field of energy and environmental studies. A detailed survey of over 100 such studies has been provided by Zhou et al. (2008). Ramanathan compared energy efficiency of different transport modes in the Indian context using DEA (Ramanathan 2008). In another paper, Ramanathan studied efficiency with respect to energy consumption and $\mathrm{CO}_{2}$ emission in North Africa and countries of Middle East (Ramanathan 2005). Mukherjee presented several DEA models for analysis of used energy efficiency in US manufacturing firms (Mukherjee 2008). DEA has been also used for benchmarking the electric utilities in Europe and northern Europe (Jamasb, Pollitt 2003; Edvardsen, Førsund 2003).

DEA was applied Boyd and Pang examined the relationship between productivity and energy efficiency for glass industry (Boyd, Pong 2000). Blomberg et al. (2012) used DEA to assess policy implications on energy efficiency in Swedish pulp and paper industry. Lee (2008) applied DEA with regression for benchmarking energy efficiency of government buildings in Taiwan. Lee and Lee (2009) used regression with 2-stage DEA for benchmarking the performance of building management system with climate adjusted energy consumption. Kim compared the energy consumption efficiency of Asia-Pacific countries using DEA (Taeho 2008). Hu and Kao used DEA for setting energy saving targets for APEC countries with capital stock, labour employment and energy consumption as inputs and GDP as output (Hu, Kao 2007). Onut and Soner used input oriented CRS DEA for energy efficiency assessment for the Antalya regions of hotel in Turkey with occupancy rates and annual total revenue as outputs (Onut, Soner 2006). Energy efficiency development of non-energy-intensive industries in Germany and Columbia was studied by Martinez with $\mathrm{CO}_{2}$ emissions as undesirable output and using three different DEA model viz. CCR, cost minimization and slack based model with undesirable output (Martínez 2011). Mandal and Madheshwaran (2011) measured energy use efficiency with undesirable outputs for Indian cement industry. Yang and Pollitt used four different methods based on DEA accompanied with other techniques like SFA, regression and Tobit regression to incorporate undesirable output and incontrollable variables in order to evaluate the performance of Chinese 
coal-fired power plants (Yang, Pollitt 2009). Most of the above-mentioned studies were conducted from an academic perspective and were not aimed at developing an alternate implementable approach to target setting. In contrast, this paper assesses the applicable methodology for energy efficiency target setting and suggests development of a methodological approach based on data envelopment analysis (DEA).

\section{Data collection and description}

All of the data was obtained from the Annual report and Directors' report of the respective firms. This was accessed through the CAPITALINE database which gather this information Cement Manufacturers' Assocoation's publication "Cement Statistics" for the duration from year 2007 to 2010 was also used to get relevant plant/firm level information. The information on the process involved (wet or dry) was confirmed from the respective websites of firms.

The data collected for the cement producing firms includes raw material consumed, power and fuel consumed, power and fuel expenditure, finished products and capacity and energy consumption per unit production. The important criteria for data collection was the continuity of data from year 2007 to 2010. Data for a total of 31 firms was collected. Energy information required special focus in order to avoid double counting of the purchased fuel used for electricity generation and as thermal fuel. Cement to be traded was not mentioned clearly into the raw materials, and was matched from the finished products data from their annual reports. For study involving energy consumption, plant-level data is most apt. But because of its unavailability, firm level data was collected. Plant level data could not be accessed from BEE.

Detailed information about the input and output consists of the quantity of the fuel (coal, diesel, furnace oil and gaseous fuels) and for in-house electricity generated from diesel generators and steam turbines, quantity of the raw material (limestone, slag, fly-ash, and other materials including pozzolana material, laterite etc.) purchased/consumed and its unit price and total cost, total clinker production 
(only for a few firms) and clinker sold, cement production and capacity. For aggregating the fuel consumption, all of the fuels were converted into energy in MTOE (metric tonne of oil equivalent). Since the quality of the fuels used and their respective calorific values were not provided, the conversion was done on the basis of the calorific values as constant as per the Sub Ordinate 394 (E) by the Ministry of Power. To back-track the coal consumption by the steam turbines, heat rate was assumed at $2717 \mathrm{kCal} / \mathrm{kWh}$ as specified in the PAT booklet. To back-track the diesel consumption in diesel generators, the specific fuel consumption was assumed to be $0.16 \mathrm{~kg} / \mathrm{kWh}$.

Since quality of coal can vary, exercise was done to identify the quality of the coal consumed based on the unit cost to the firm. Almost all firms reported a coal quality of Grade-A for respective year. A constant GCV (gross calorific value) of 3.8 million $\mathrm{kCal} / \mathrm{MT}$ was assumed for all of the plants showing a coal of Grade-A quality. As for the firms showing coal quality different from Grade-A, their respective calorific values were used. For other firms a coal constant was used to ascertain coal quality wherever feasible.

To calculate the SEC for the cement production, the energy consumed for the clinker that was sold was deducted from the overall calculation of SEC. Similarly, limestone consumed in the sold clinker was also deducted from the total limestone consumption on a proportionate basis.

From the compiled data, baseline data was prepared as per the BEE methodology for PAT. For preparing baseline data, an average of three years data was used i.e. for years 2008, 2009 and 2010. Wherever data for any of these years was incongruent or unavailable, data from year 2007 was included. The firms for which only one or two year data was available out of four years, the mean for the baseline was calculated by including those one or two year observations only. The sample consists of the plants having dry manufacturing process. 


\section{Suggested methodology}

The methodology proposed for calculating target Specific Energy Consumption (SEC) consists of a 2-stage process. For the first stage, a method close to the approach adopted by BEE for target setting under the PAT mechanism to set Sector Energy Reduction Target (SERT), with a slight variation is described in the subsection below. In the second stage, reduction targets for individual firms are set based on an alternate approach developed using DEA. Further, a differentiation is also made between the energy purchased by the plant against the energy finally consumed in the process after any conversion (for e.g. use of oil or coal to produce electricity). Thus, final SEC targets are estimated for "purchased energy" as well as for "process energy".

\subsection{Stage 1- Sector Energy Reduction Target (SERT)}

BEE assigned a reduction target of 0.62 million MTOE/year for the cement sector, which had a total energy consumption of 14.48 million MTOE/year in the baseline year 2009-2010, to be achieved at the end of first PAT cycle in March 2015. This is equivalent to a sectorial reduction target of $4.28 \%$ on a pro-rata basis. We have applied the same percentage reduction target to the total energy consumption of the sample of firms in our dataset.

Energy saving targets for the DCs, under the PAT mechanism is given as a percentage reduction from the baseline SEC for the respective DC. Based on the analysis done on the notified targets of the DCs in the cement sector and the information given in PAT consultation document (Bureau of Energy Efficiency 2011), it is inferred that this percentage reduction target for individual DCs is the product of relative SEC and a common "multiplying factor". This multiplying factor is different for each sub-sector as the reduction target is different for every respective sub-sector. We apply this approach for the sample of dry process cement manufacturing plants as a sub-sector of the cement sector. However, we do not further divide our sample in sub-sectors as all the data corresponds to dry process. Target energy reduction for the sample, SEC for each firm and the multiplying factor are calculated using estimated baseline data as follows in equation (6) to (8). 


$$
\begin{gathered}
E_{S}=E_{T}-\sum_{i}\left(O_{i} \times S E C_{i}^{t}\right) \\
S E C_{i}^{t}=S E C_{i} \times\left(1-\left(X \times S E C_{i}^{n}\right)\right)
\end{gathered}
$$

Using equation (7) in equation (6) yields the following relation:

$$
X=\left[100 \times E_{S}\right] / \sum_{i}\left(O_{i} \times S E C_{i} \times S E C_{i}^{r}\right)
$$

Where, $\quad i \in(1,2 \ldots \ldots n) n$ being number of firms in the sample $X=$ Multiplying Factor

$E_{T}=$ Total energy consumption in the sample (MTOE)

$E_{S}=$ Total energy saving target for sample (MTOE)

$O_{i}=$ Output of the firm (tonnes)

$S E C_{i}=$ Specific energy consumption of the firm (MTOE/tonne)

$S E C_{i}^{t}=$ Target Specific energy consumption

$S E C_{i}^{r}=$ Relative SEC i.e. ratio of firm's SEC to lowest SEC in sample.

Total energy consumption by the firms in our sample is 7136156.13 MTOE. The target energy saving for this sample, based on the BEE's percentage target reduction for the sector would be 305427.48 MTOE (4.28\% of total energy consumption). For the sample of 31 firms in our study, the calculated value of the multiplying factor comes out to be 2.494 when purchased energy is considered and 3.406 when the process energy input is considered. Based on the BEE's approach, the firm with the least SEC is given a percentage reduction of $2.494 \%$ or $3.406 \%$, depending on the energy input consideration, and all other units will have a reduction target higher than this value.

A deviation from the BEE methodology has been adopted for the energy consumption target. Instead of different reduction target for different firms, a common minimum percentage reduction target has been set for all firms at Stage-1, which is equal to the target set under BEE methodology for the firm having least SEC. This is to ensure a minimum reduction in energy consumption even for those firms which will be technically efficient and will form efficiency frontier in the DEA analysis. 


\subsection{Stage 2- DEA based Target Setting for individual firms}

SECs of DCs vary depending on a number of controllable and non-controllable factors. Controllable factors include input mix, technology, operational practises, output mix, etc. Non-controllable factors include ambient conditions, market conditions, regulations etc. We include some of the controllable factors in DEA. DEA results provide targets for the controllable factors such as quantities of inputs (or output) variables by a firm to reach the efficiency frontier. For our study, only targets for energy consumption are counted for. The use of other inputs in DEA analysis gives overall efficiency scores which result in identification of energy saving potential for the firms in a holistic manner. Achieving the overall efficiency may or may not contribute to the purpose of energy saving in a market based environment and in an economically viable way. Hence, the targets are set only for energy consumption, not for other inputs.

After equal percentage energy reduction target for each DC in stage-1, the remaining sectorial reduction target to be achieved in stage-2 is allocated to the DCs based on potential energy saving projections from DEA application. The remaining stage-2 reductions are distributed amongst the inefficient DCs on a pro-rata basis of the total energy saving projection from the DEA. The DCs which form the efficiency frontier have zero additional energy reduction target and hence, don't have any reduction targets in stage-2. This is different from the BEE methodology where only one DC can have the least reduction target in a sector/sub-sector.

\subsection{DEA model}

Input and output variables for DEA are selected by considering the purpose of the study and the information availability. The purpose of the DEA application here is to find out the target reduction for SEC of a plant based on the performance of its peers by forming an efficiency frontier.

Cement production (in tonnes) of the plant is used as the only output variable in the study. Cement plants in India produce a mix of cements like OPC, PPC, etc. Although more than one output can be used in DEA, we use only one because of the non-availability of data. 
Plant capacity affects the efficiency of the plant, which is not always because of economies of scale. Setting the capacity is mostly an economic decision which is dependent on various non-managerial and market variables, and other environmental factors such as availability of raw material at the plant-site. It can also be considered as a proxy for net assets of a plant and for the technology incorporated which can't be changed significantly in the short run. Hence capacity is considered and used as a non-controllable variable for study.

Another variable which is of importance is the vintage of the plant which is the year of establishment of the plant. Although it is assumed that the vintage adversely affects the efficiency of the plant due to old technologies and wear-tear, but plants do improve their machinery and replace the old ones with the more productive and efficient ones. Hence, true effect of vintage is difficult to measure. For benchmarking studies where one plant is compared with another, consideration of vintage will result in undue advantage to inefficiency and regressive approach to modernization. Therefore, vintage is not included as an environmental variable or non-controllable variable. The data does not give any information on the age of the plant but only of the registration date of the firm. This data about firm does not give any proxy for vintage.

The total energy consumption of the plant is calculated by converting all energy inputs into tonnes of oil equivalent. Distinction is made to identify the "purchased energy" input and the "production energy" input. The former refers to the energy inputs purchased and later accounts for energy conversion, for e.g. by converting oil or coal to electricity. This allows us to analyse and set energy efficiency targets based on these two perspectives. Plants generate electricity for their own consumption from the primary energy inputs. This distinction will help us identify thermal energy and electricity requirements separately. Therefore, four types of energy input baskets are considered for DEA. These are described later in the section.

The objective of setting targets is to reduce input energy. Hence, an input oriented approach is adopted for DEA. Capacity considered as a non-controllable variable. Hence, an "input-oriented non-controllable model with variable return to scale" DEA model is adopted. It is described as follows, 
Minimize $\theta$

$$
\begin{array}{cc}
\text { Subject to, } p_{0} & \leq P \lambda \\
\theta e_{i_{0}} & \geq E_{i} \lambda(i=1,2) \\
\theta l_{0} & \geq L \lambda \\
c_{0}=C \lambda \quad & (10) \\
& \lambda \geq 0, \sum \lambda=1\left(\lambda_{1}, \lambda_{2}, \ldots . \lambda_{n}\right)
\end{array}
$$

Here $P$ is the production output matrix-vector, $L$ is the limestone consumption matrix vector, $\lambda$ is a non-negative vector, ' $n$ ' denotes the number of firms and $C$ is the capacity matrix-vector (for a non-controllable variable). $E_{i}$ is the energy consumption input matrix-vector where ' $i$ ' denotes the types of energy input as electricity, fuel or as total energy input. For any $D M U_{0}$ to be evaluated, $e_{i}, l_{0}, c_{0}$ and $p_{0}$ are the corresponding vectors for the observed values of energy consumption, limestone consumption, capacity and production of the DMU under consideration, respectively. Four alternate energy input formulations are used giving four different versions of the model as given in next table:

\section{Table 4. Energy input formulations}

\begin{tabular}{|c|c|c|c|c|c|c|}
\hline Case & Energy Input Formulation (MTOE) & $\begin{array}{c}\text { Number of } \\
\text { Energy } \\
\text { Inputs }\end{array}$ & E & $\mathbf{E}_{\mathbf{1}}$ & $\mathbf{E}_{\mathbf{2}}$ & Limestone \\
\hline 1 & Total energy purchased & 1 & $\checkmark$ & - & - & $\checkmark$ \\
\hline 2 & Purchased electricity and purchased fuels & 2 & - & $\checkmark$ & $\checkmark$ & $\checkmark$ \\
\hline 3 & $\begin{array}{c}\text { Total energy consumed for production } \\
\text { process }\end{array}$ & 1 & $\checkmark$ & - & - & $\checkmark$ \\
\hline 4 & $\begin{array}{c}\text { Total electricity used in production process } \\
\text { and fuels consumed in production process }\end{array}$ & 2 & - & $\checkmark$ & $\checkmark$ & $\checkmark$ \\
\hline
\end{tabular}

Source: Authors' own elaboration.

In case 1 , there is one energy variable where $\mathrm{E}$ represents total energy purchased. In case 2 , there are two energy variables where $E_{1}$ represents purchased electricity and $\mathrm{E}_{2}$ represents purchased fuel. With one input variable in case 3, E represents total energy used for production process which is the sum of purchased electricity and electricity that generated in-house, and other fuels (in tonnes of oil equivalent) excluding fuel used for generation of electricity. For Case $4, \mathrm{E}_{1}$ represents total electricity consumed and $\mathrm{E}_{2}$ represents fuels consumed only in 
production process excluding the amount used in electricity generation. Total Electricity includes purchased and electricity generated in-house.

\section{Results and Discussions}

Following table summarises the results of the adopted DEA based methodology (with all energy input scenarios). It also gives a comparison of the targets adopting BEE's methodology. Since the BEE focuses only on the energy efficiency targets, we have not included the Limestone reduction targets in our result analysis.

As per BEE methodology, the highest percentage SEC reduction target is for unit CD_031 having SEC of 0.108 MTOE/tonnes and relative SEC of 2.824 and having target reduction of $7.05 \%$. For Case-1, 13 DCs form the efficiency frontier having least and highest SEC reduction target to be $2.49 \%$ and $17.86 \%$. For Case-2, efficiency frontier is formed by 14 DMUs. The highest SEC \% reduction target is $19.044 \%$.

For Case-3, the efficiency frontier is formed by 11 DCs. The SEC \% reduction target for the firms forming efficiency frontier, based on the process energy based SEC, is $3.41 \%$. But when the reduction targets were converted on the purchased energy based SEC, the SEC \% reduction targets came out to be different for the firms forming efficiency frontier. Maximum target is of $12.37 \%$ and minimum is $2.27 \%$, based on purchased energy based SEC. For Case-4, the efficiency frontier in this case is formed by 14 DMUs. The DEA SEC reduction targets vary from a highest of $15.32 \% 013$ to a lowest of $2.27 \%$.

An important observation in Case- 3 and Case- 4 is that some of the firms are having final targets less than $3.41 \%$ (e.g. $2.27 \%$ for CD_015 and $2.63 \%$ for CD_002), which is corresponding to the minimum target from the BEE methodology for the process energy based SEC. When total energy input is segregated into type of energy used viz. electricity and fuel, in most of the units, the energy consumption calculated based on the purchased energy input comes out to be higher than that of the energy consumption based on process energy input. This difference is accounted to the conversion inefficiencies from the losses in making electricity from fuel. 
Table 5. SEC reduction targets for different energy inputs

\begin{tabular}{|c|c|c|c|c|c|c|c|c|c|}
\hline \multirow{2}{*}{$\begin{array}{l}\text { Unit } \\
\text { Code }\end{array}$} & \multirow{2}{*}{$\begin{array}{l}\text { Limestone } \\
\text { per tonne } \\
\text { of cement } \\
\text { production } \\
\text { (Tonnes) }\end{array}$} & \multirow{2}{*}{$\begin{array}{c}\text { SEC } \\
\text { (Purchased } \\
\text { Energy) } \\
\text { (MTOE/ } \\
\text { Tonnes) }\end{array}$} & \multirow{2}{*}{$\begin{array}{c}\text { SEC } \\
\text { (Process } \\
\text { Energy) } \\
\text { (MTOE/ } \\
\text { Tonnes) }\end{array}$} & \multirow{2}{*}{$\begin{array}{c}\text { Share of } \\
\text { purchased } \\
\text { electricity in } \\
\text { total } \\
\text { electricity } \\
\text { consumption }\end{array}$} & \multicolumn{5}{|c|}{ SEC Reduction Target (\%) } \\
\hline & & & & & $\begin{array}{c}\text { BEE } \\
\text { Methodology }\end{array}$ & $\begin{array}{c}\text { DEA } \\
\text { based } \\
\text { Case- } \\
1\end{array}$ & $\begin{array}{c}\text { DEA } \\
\text { based } \\
\text { Case- } \\
2\end{array}$ & $\begin{array}{c}\text { DEA } \\
\text { based } \\
\text { Case- } \\
3\end{array}$ & $\begin{array}{c}\text { DEA } \\
\text { based } \\
\text { Case- } \\
4\end{array}$ \\
\hline CD_001 & 0.848 & 0.070 & 0.070 & 100.00 & 4.57 & 12.13 & 11.97 & 9.09 & 9.07 \\
\hline CD_002 & 1.068 & 0.055 & 0.042 & 10.79 & 3.60 & 2.59 & 2.49 & 2.63 & 2.63 \\
\hline CD_003 & 1.149 & 0.057 & 0.056 & 87.26 & 3.75 & 2.49 & 2.49 & 5.76 & 5.66 \\
\hline CD_004 & 1.050 & 0.061 & 0.050 & 30.79 & 3.96 & 2.49 & 2.49 & 2.79 & 2.79 \\
\hline CD_005 & 1.152 & 0.064 & 0.049 & 26.71 & 4.16 & 2.49 & 2.49 & 2.61 & 2.61 \\
\hline CD_006 & 0.612 & 0.068 & 0.056 & 21.96 & 4.45 & 2.49 & 2.49 & 2.82 & 2.82 \\
\hline CD_007 & 0.762 & 0.071 & 0.065 & 74.20 & 4.64 & 8.37 & 8.96 & 6.52 & 7.48 \\
\hline CD_008 & 1.131 & 0.058 & 0.048 & 41.41 & 3.82 & 4.76 & 4.84 & 4.72 & 5.39 \\
\hline$\overline{C D \_009}$ & 1.176 & 0.053 & 0.043 & 32.22 & 3.49 & 2.49 & 2.49 & 3.72 & 3.81 \\
\hline CD_010 & 0.945 & 0.038 & 0.038 & 100.00 & 2.49 & 2.49 & 2.49 & 3.41 & 3.41 \\
\hline CD_011 & 1.447 & 0.074 & 0.062 & 33.83 & 4.87 & 14.21 & 13.14 & 8.33 & 7.46 \\
\hline CD_012 & 0.069 & 0.070 & 0.070 & 95.32 & 4.60 & 2.49 & 2.49 & 3.39 & 3.39 \\
\hline CD_013 & 1.330 & 0.094 & 0.090 & 72.33 & 6.14 & 17.68 & 18.97 & 12.37 & 15.32 \\
\hline CD_014 & 1.320 & 0.099 & 0.089 & 43.39 & 6.45 & 13.75 & 16.01 & 7.83 & 9.06 \\
\hline CD_015 & 1.190 & 0.058 & 0.038 & 5.36 & 3.76 & 2.49 & 2.49 & 2.27 & 2.27 \\
\hline CD_016 & 1.297 & 0.073 & 0.063 & 16.54 & 4.76 & 14.78 & 10.28 & 8.31 & 9.52 \\
\hline CD_017 & 1.321 & 0.064 & 0.055 & 45.94 & 4.20 & 2.49 & 2.49 & 3.91 & 2.93 \\
\hline CD_018 & 0.928 & 0.058 & 0.058 & 100.00 & 3.77 & 9.13 & 7.11 & 7.25 & 3.41 \\
\hline CD_019 & 0.896 & 0.059 & 0.059 & 99.40 & 3.84 & 2.49 & 2.49 & 3.40 & 3.40 \\
\hline CD_020 & 1.263 & 0.076 & 0.071 & 75.71 & 4.94 & 17.13 & 14.78 & 10.67 & 9.52 \\
\hline CD_021 & 1.269 & 0.094 & 0.094 & 100.00 & 6.13 & 16.99 & 16.64 & 11.75 & 13.10 \\
\hline CD_022 & 1.353 & 0.084 & 0.084 & 99.91 & 5.46 & 15.39 & 16.26 & 10.91 & 12.47 \\
\hline CD_023 & 0.997 & 0.057 & 0.053 & 63.27 & 3.76 & 9.99 & 6.72 & 6.49 & 7.20 \\
\hline CD_024 & 1.332 & 0.088 & 0.088 & 100.00 & 5.73 & 17.86 & 19.04 & 12.27 & 14.56 \\
\hline CD_025 & 1.090 & 0.062 & 0.060 & 99.67 & 4.08 & 7.92 & 7.54 & 10.18 & 10.65 \\
\hline CD_026 & 2.054 & 0.094 & 0.094 & 99.85 & 6.15 & 5.68 & 5.60 & 6.48 & 3.41 \\
\hline CD_027 & 0.932 & 0.063 & 0.063 & 99.15 & 4.11 & 2.49 & 2.49 & 3.40 & 3.40 \\
\hline CD_028 & 1.022 & 0.063 & 0.062 & 96.30 & 4.10 & 7.75 & 8.03 & 6.22 & 7.13 \\
\hline CD_029 & 1.396 & 0.057 & 0.048 & 40.43 & 3.70 & 2.49 & 2.49 & 2.89 & 2.89 \\
\hline CD_030 & 0.617 & 0.053 & 0.051 & 91.76 & 3.45 & 2.49 & 2.49 & 3.31 & 3.31 \\
\hline CD_031 & 1.639 & 0.108 & 0.107 & 98.60 & 7.05 & 7.95 & 6.64 & 6.48 & 8.37 \\
\hline
\end{tabular}

Source: Authors' own elaboration.

The inefficiencies in generation are reflected in energy consumptions of the plants. The electricity produced through a Captive Power Plant (CPP) saves Transmission and Distribution (T\&D) losses, which otherwise would be borne at system level purchases by other consumers. This gives rise to two important considerations. One, the inefficiencies in generations are required to be reduced, but 
only after being accounted with the savings in T\&D losses at the power system level. Second, a direct comparison between plants with and without a CPP cannot be a right approach.

Figure 2. SEC (purchased energy) vs. BEE methodology based SEC reduction $\%$

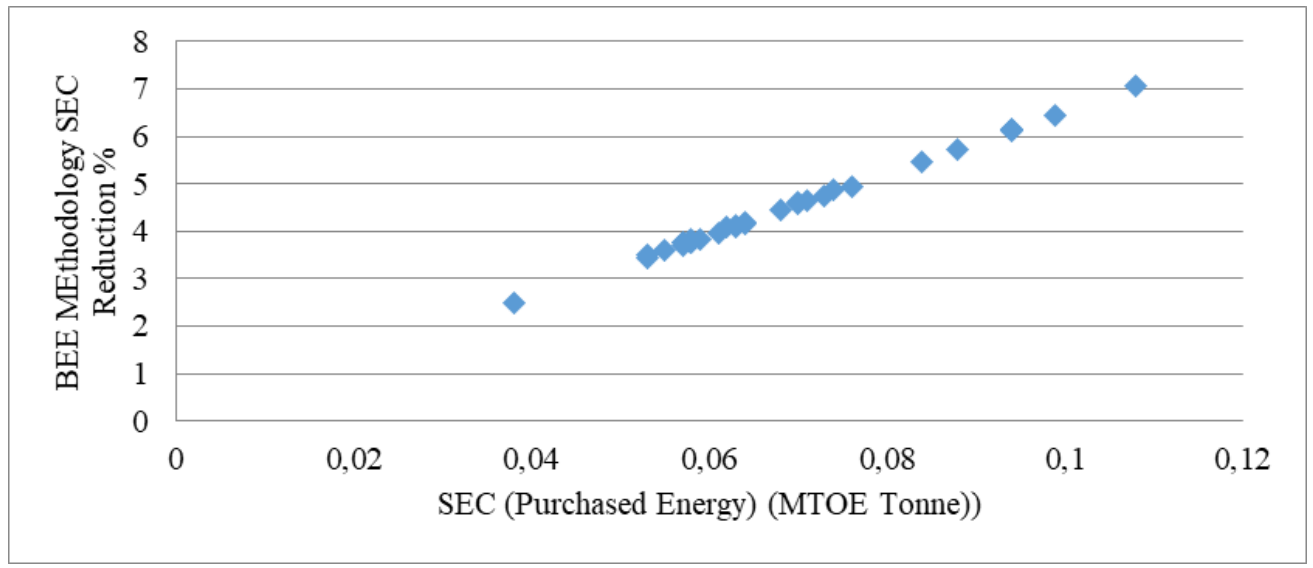

Source: Authors' own elaboration.

Figure 3. SEC (purchased energy) vs. Case-1 SEC reduction \%

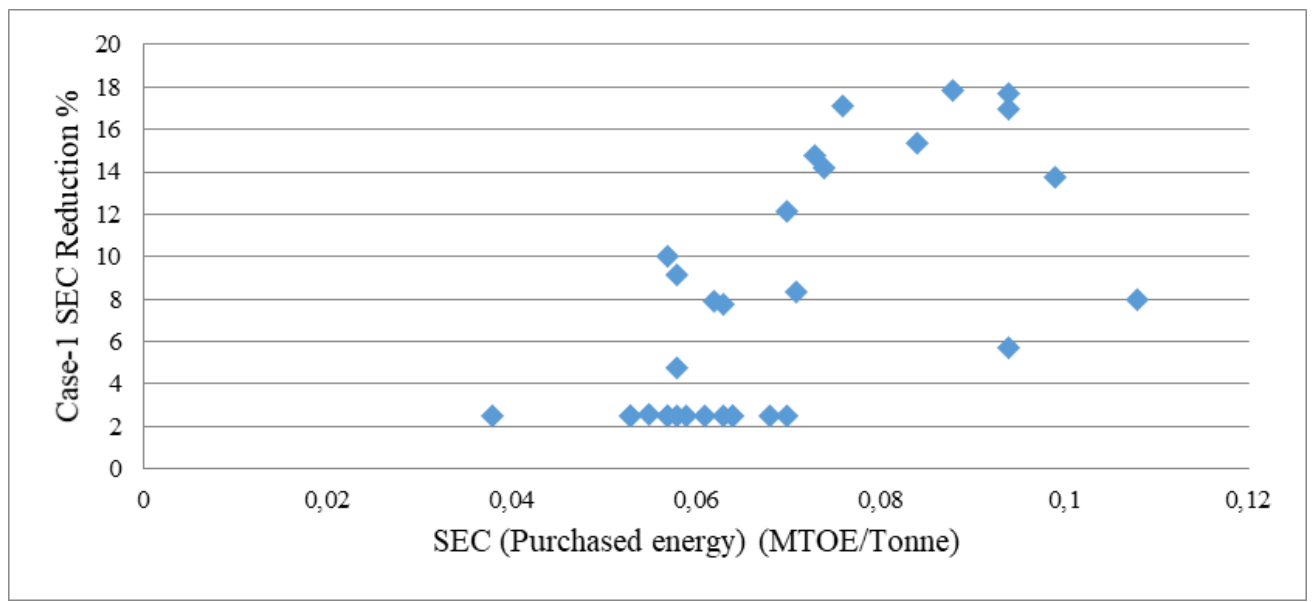

Source: Authors' own elaboration. 
Figure 4. SEC (purchased energy) vs. Case-2 SEC reduction \%

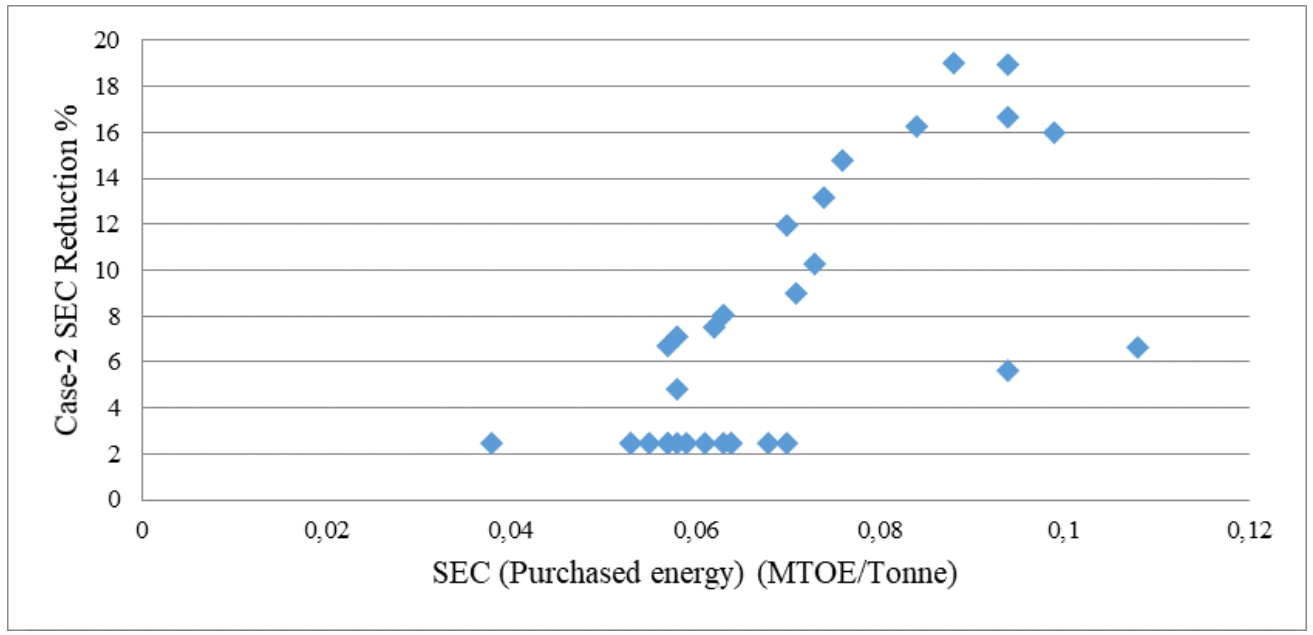

Source: Authors' own elaboration.

Figure 5. SEC (purchased energy) vs. Case-3 SEC reduction \%

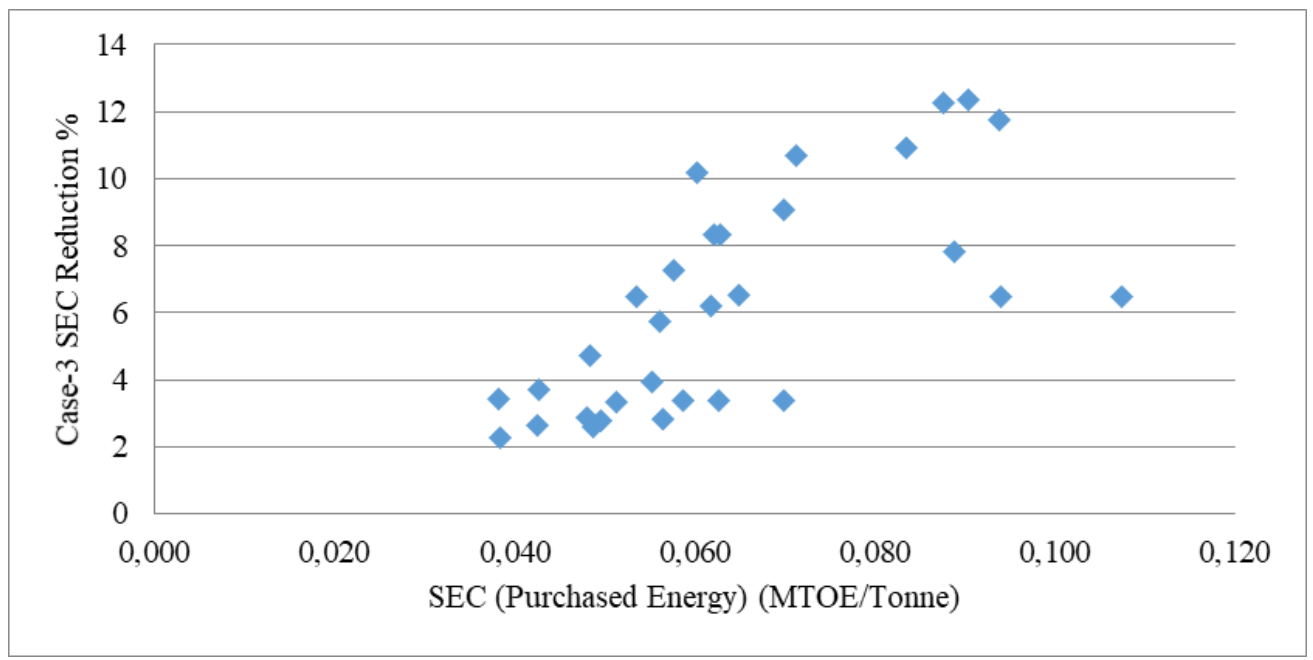

Source: Authors' own elaboration. 
DEA BASED APPROACH TO SET ENERGY EFFICIENCY TARGET UNDER PAT ...

Figure 6. SEC (purchased energy) vs. Case-4 SEC reduction \%

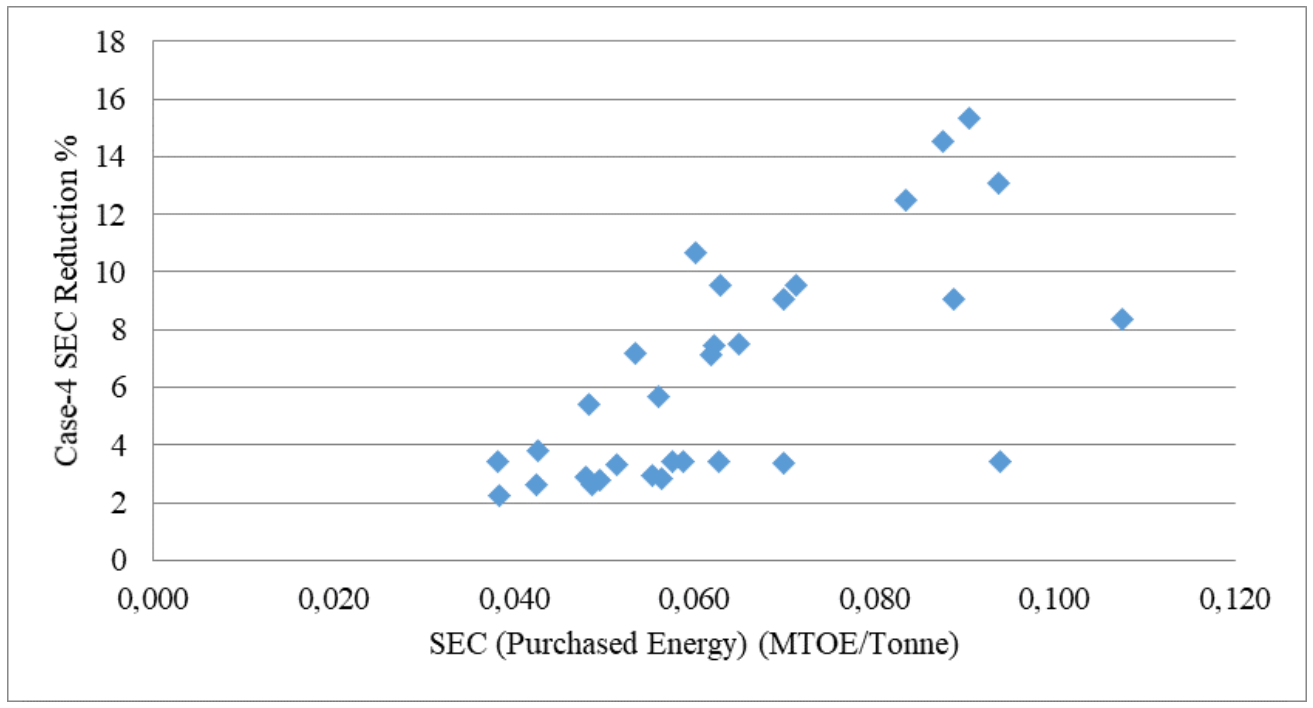

Source: Authors' own elaboration.

Figure 7. SEC (process energy) vs. Case-3 SEC reduction \%

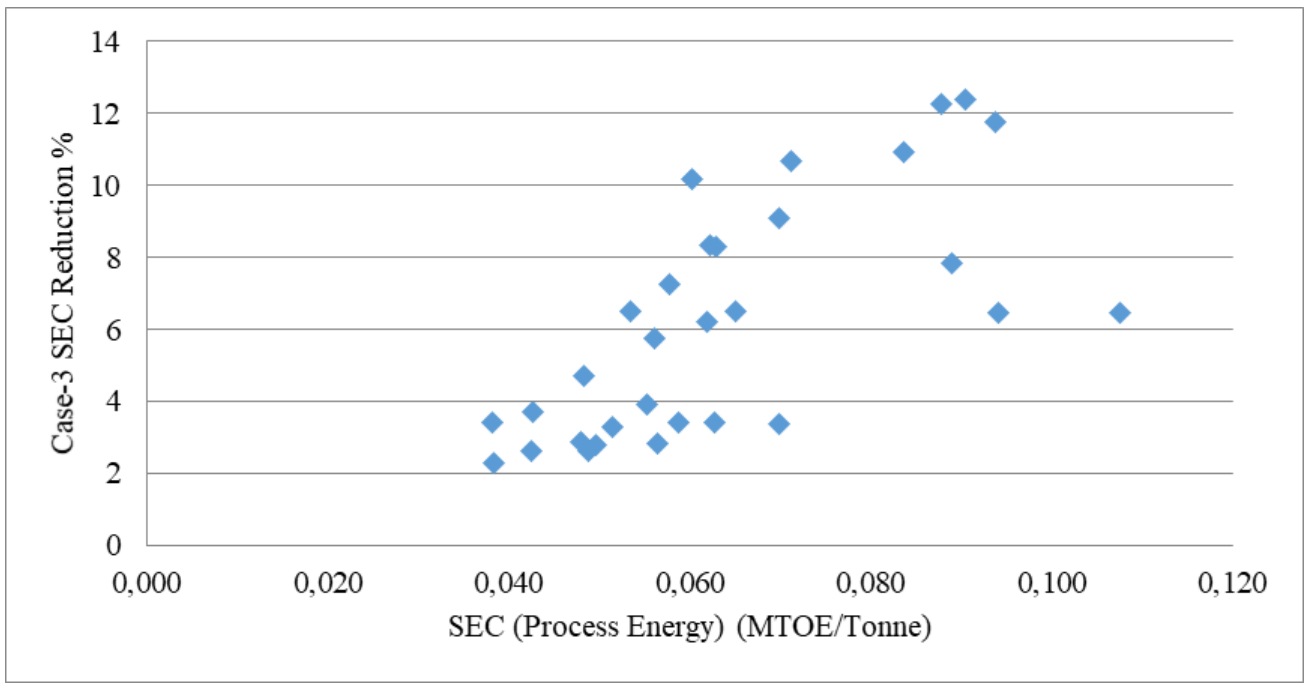

Source: Authors' own elaboration. 
Figure 8. SEC (process energy) vs. Case-4 SEC reduction \%

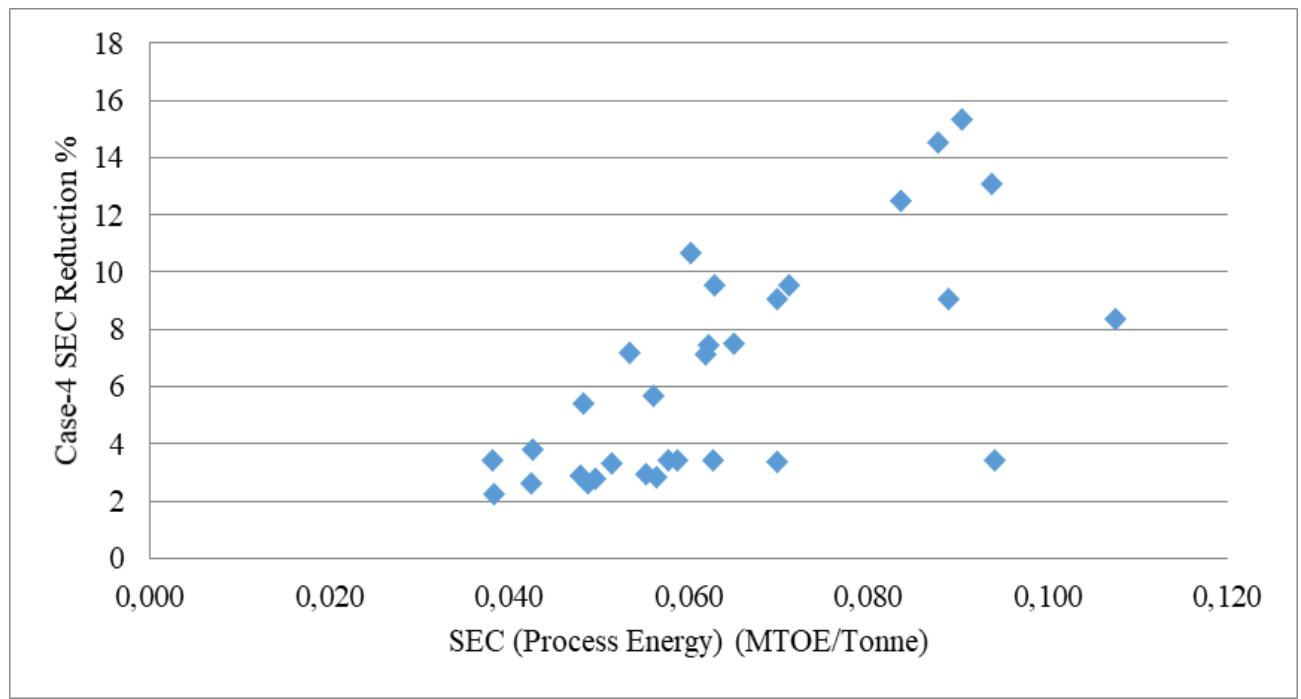

Source: Authors' own elaboration.

Figure 2 shows a strong positive correlation with value of correlation coefficient to be 1 between SEC reduction percentages based on BEE methodology and purchased energy SEC. Figure 3 and Figure 4 shows Case-1 and Case-2 SEC reduction percentages with purchased energy SEC showing moderately positive correlation and having values of correlation coefficients to be 0.65 and 0.69 respectively. Figure 5 and Figure 6 shows Case- 3 and Case- 4 SEC reduction percentages with purchased energy SEC showing moderately positive correlation and having values of correlation coefficients to be 0.65 and 0.64 respectively. Figure 7 and Figure. 8 shows Case- 3 and Case- 4 SEC reduction percentages with process energy SEC showing moderately positive correlation and having values of correlation coefficients to be 0.69 and 0.68 respectively. Overall, the DEA based method showed a moderately positive correlation for different cases and having maximum values for process based energy inputs and process energy based SEC. 


\section{Conclusion}

Energy efficiency plays an important role in achieving energy security and addressing environmental concerns of the country. PAT is an ambitious market based measure for improving energy efficiency in India's energy-intensive industrial sectors. The cement plants in India are the most efficient in world country-wise, but there is still a great scope of improvement as compared to the world benchmarks.

The DEA method adopted for this paper gives energy saving target not just on the basis of SEC, but also considers other criteria like capacity and raw material. The methodology does not always set high targets for the plants having high specific energy consumption, as it also considers the DEA based technical efficiency for target setting. DEA encompasses other factors and sets the targets holistically. The methodology adopted by BEE ignores the impact of factors like raw material composition and quality, internal consumption of products by the plant itself, inhouse energy conversion etc. These factors can't be ignored while setting the targets.

As BEE sets plant-specific targets, it also gives importance to the factors like vintage and the old technology used in the plants. Older plants are less efficient and there has been a sympathetic look towards them in target setting. This should not be the case as it can be considered as a reward for inefficiencies and obsoleteness. Such older inefficient plants used appropriate targets to incentivize in technological improvement. It is desirable to implement a credible mechanism for target setting for energy efficiency and strict compliance for the same.

Another important issue is the comparatively short duration of the three-year for the PAT cycle, resulting in adoption of easy-fix methods adopted by the plants. Long term regulated certainty under the PAT mechanism supported with more stringent targets would provide incentives for adopting a long term strategy for energy efficiency improvement. Blending fly-ash and slag reduces the SEC, but does not help the plants in the long run. The target accomplishment should be sufficient to make economic investments profitable in the long run. Therefore, the duration of PAT cycle should be increased.

Unavailability of plant level data remains a limitation of this study is that of the data. The firm-level data does not give the information about the pattern and 
behaviour of the plants. As the firm-level data covers the overall energy expenditure across multiple plants, plant level differences could not be investigated.

The energy efficiency regulator i.e. BEE needs to take a broader perspective to make data accessible so that areas for improvement in PAT methodology can be identified. Data access can be provided by without revealing the true identity of the plants. Given a fairly large number of DCs in each sector, a fair degree of anonymity can still be ensured.

\section{References}

Alacantara V., Duarte R. (2004), Comparison of energy intensities in European Union countries. Results of a structural decomposition analysis, „Energy Policy”, vol. 32 no. 2, pp. 177-189.

Ang B.W., Zhang F.Q. (2000), A survey of index decomposition analysis in energy and environmental studies, „Energy”, vol. 25 no. 12, pp. 1149-1176.

Babusiaux D., Pierru A. (2007), Modelling and allocation of $\mathrm{CO}_{2}$ emissions in a multiproduct industry. The case of oil refining, „Applied Energy”, vol. 84 no. 7, pp. 828-841.

Blomberg J., Henriksson E., Lundmark R. (2012), Energy efficiency and policy in Swedish pulp and paper mills. A data envelopment analysis approach, „Energy Policy”, vol. 42, pp. 569-579.

Bohringer C., Rutherford T.F. (2008), Combining bottom-up and top-down, „Energy Economics”, vol. 30 no. 2, pp. 574-596.

Boyd G.A., Pang J.X. (2000), Estimating the linkage between energy efficiency and productivity, „Energy Policy”, vol. 28 no. 5, pp. 289-296.

Bureau of Energy Efficiency (2011), PAT consultation document, http://220.156.189.23/NMEEE/PAT\%20Consultation\%20Document_10Jan2011.pdf [10.02.2018].

Bureau of Energy Efficiency (2012), PAT Booklet, „PAT Perform, Achieve and Trade”, https://beeindia.gov.in/sites/default/files/PAT\%20PPT_0.pdf [July 2012]

CEIC (2013), India Premium Database, https://www.ceicdata.com/en/blog/expansion-population-dataindia-premium-database [10.03.2018].

Charnes A., Cooper W.W., Rhodes E. (1978), Measuring the efficiency of decision making units, „European Journal of Operational Research”, vol. 2 no. 6, pp. 429-444.

Edvardsen D.F., Førsund F.R. (2003), International benchmarking of electricity distribution utilities, „Resource and Energy Economics”, vol. 25 no. 4, pp. 353-371.

Farrell M.J. (1957), The measurement of productive efficiency, „Journal of the Royal Statistical Society", vol. 120 no. 3, pp. 253-290. 


\section{DEA BASED APPROACH TO SET ENERGY EFFICIENCY TARGET UNDER PAT ...}

Frei C.W., Haldi P.H., Sarlos G. (2003), Dynamic formulation of a top-down and bottom-up merging energy policy model, „Energy Policy”, vol. 31 no. 10, pp. 1017-1031.

Gielen D., Taylor P. (2009), Indicators for industrial energy efficiency in India, „Energy”, vol. 34 no. 2, pp. 962-969.

Greening L.A., Boyd G., Roop J.M. (2007), Modeling of industrial energy consumption. An introduction and context, „Energy Economics”, vol. 29 no. 4, pp. 599-608.

Henning D., Trygg L. (2008), Reduction of electricity use in Swedish industry and its impact on national power supply and European $\mathrm{CO}_{2}$ emissions, „Energy Policy”, vol. 36 no. 7, pp. 2330-2350.

Hu J.L., Kao C.H. (2007), Efficient energy-saving targets for APEC economies, „Energy Policy”, vol. 35 no. 1, pp. 373-382.

International Energy Agency (2007), Tracking industrial energy efficiency and $\mathrm{CO}_{2}$ emissions, https://www.iea.org/publications/freepublications/publication/tracking_emissions.pdf, pp. 140-163 [10.03.2018].

International Energy Agency (2016), World Energy Statistics 2016, http://www.oecd.org/publications/world-energy-statistics-25183885.htm, pp. II.6-II.320 [10.03.2018].

Jamasb T., Pollitt M. (2003), International benchmarking and regulation. An application to European electricity distribution utilities, „Energy Policy”, vol. 31 no. 15, pp. 1609-1622.

Lawrence Berkeley National Laboratory (2010), Strategies for low carbon growth in India. Industry and non-residential sectors, https://ies.lbl.gov/sites/all/files/low-co-growth-india-2011.pdf [10.03.2018].

Lee W.S. (2008), Benchmarking the energy efficiency of government buildings with data envelopment analysis', „Energy and Buildings, vol. 40, pp. 891-895.

Lee W.S., Lee K.P. (2009), Benchmarking the performance of building energy management using data envelopment analysis, „Applied Thermal Engineering”, vol. 29 no. 16, pp. 3269-3273.

Lescaroux F. (2008), Decomposition of US manufacturing energy intensity and elasticities of components with respect to energy prices, „Energy Economics”, vol. 30 no. 3, pp. 1068-1080.

Madlool N.A., Saidur R., Hossain M.S., Rahim N.A. (2011), A critical review on energy use and savings in the cement industries, „Renewable and Sustainable Energy Reviews”, vol. 15 no. 4, pp. 2042-2060.

Mandal S.K., Madheswaran S. (2011), Energy use efficiency of Indian cement companies. A data envelopment analysis, „Energy Efficiency”, vol. 4 no. 1, pp. 57-73.

Martínez C.I.P. (2011), Energy efficiency development in German and Colombian non-energyintensive sectors. A non-parametric analysis, „Energy Efficiency”, vol. 4 no. 1, pp. 115-131.

GOI (2012, 2013, 2014, 2015, 2016), Energy Statistics, Ministry of Statistics \& Programme Implementation (MOSPI), Government of India, New Delhi. 


\section{Anoop SINGH, Bharat SHARMA}

Mukherjee K. (2008), Energy use efficiency in US manufacturing. A nonparametric analysis, „Energy Economics", vol. 30 no.1, pp.76-96.

Nag B., Parikh J. (2000), Indicators of carbon emission intensity from commercial energy use in India, „Energy Economics”, vol. 22 no.4, pp. 441-461.

Oh W., Lee K. (2004), Causal relationship between energy consumption and GDP revisited. The case of Korea 1970-1999, „Energy Economics”, vol. 26 no. 1, pp. 51-59.

Onut S., Soner S. (2006), Energy efficiency assessment for the Antalya Region hotels in Turkey, „Energy and Buildings”, vol. 38 no. 8, pp. 964-971.

Planning Commission (2008), Cement Task Force Reports for the Eleventh Five Year Plan (20072012), http://planningcommission.nic.in/plans/planrel/11thf.htm [10.03.2018].

Ramanathan R. (2000), A holistic approach to compare energy efficiencies of different transport modes, „Energy Policy”, vol. 28 no. 11, pp. 743-747.

Ramanathan R. (2005), An analysis of energy consumption and carbon dioxide emissions in countries of the Middle East and North Africa, „Energy”, vol. 30 no. 15, pp. 2831-2842.

Shyamal P., Bhattacharya R.N. (2004), Causality between energy consumption and economic growth in India. A note on conflicting results, „Energy Economics”, vol. 26 no. 6, pp. 977-983.

Singh A. (2000), Energy efficiency and $\mathrm{CO}_{2}$ emissions mitigation potential in Indian cement industry, Working Paper No. 78, United Nations University/Institute for Advanced Studies (UNU/IAS), Tokyo.

Singh A., Parikh K.S., Parikh J. (2010), Inter-fuel substitution, industrial energy demand and carbon emissions. An analysis using firm/plant-level data for 14 industrial sectors in India, VDM Verlag Dr. Müller, Saarbrücken.

Taeho K. (2008), Efficiency at energy industry. A comparison of energy consumption efficiency among Asian Pacific countries, „Asian Journal on Quality”, vol. 9 no. 3, pp. 113-121.

Unander F. (2004), Decomposition of manufacturing energy-use in IEA countries. How do recent developments compare with historical long-term trends, „Applied Energy”, vol. 84 no. 7, pp. 771-780.

Yang H., Pollitt M. (2009), Incorporating both undesirable outputs and uncontrollable variables into DEA: The performance of Chinese coal-fired power plants, „European Journal of Operational Research”, vol. 197 no. 3, pp. 1095-1105.

Zhou P., Ang B.W., Poh K.L. (2008), Measuring environmental performance under different environmental DEA technologies, „Energy Economics”, vol. 30 no.1, pp. 1-14. 